\title{
A poética quantitativa do Formalismo Russo
}

\section{Quantitative Poetics of Russian Formalism}

Autor: Igor Pilshchikov Edição: RUS Vol. 11. № 16

Data: Setembro 2020 


\title{
A poética quantitativa do Formalismo Russo
}

\author{
Igor Pilshchikov*
}

Resumo: Este ensaio aborda a teoria formalista russa de uma perspectiva quantitativa. Seu foco está nas teorias sobre a arte verbal conforme desenvolvidas por Boris Tomachévski, Boris Eikhenbaum, Roman Jakobson e especialmente por Boris larkhó. Aborda o pioneirismo de larkhó quanto ao estudo quantitativo de aspectos do texto artístico e dos usos da estatística para tal. Além disso, trata-se do primeiro estudo sobre as contribuições de larkhó no contexto do Formalismo Russo publicado no Brasil.

\begin{abstract}
This essay approaches Russian Formalist theory from a quantitative perspective. It is focused on the theories of verbal art developed by Boris Tomashevsky, Boris Eikhenbaum, Roman Jakobson, and particularly by Boris Yarkho. The author discusses Yarkho's pioneering approach to the quantitative study of various aspects of the artistic text and the use of statistics in poetological analyses. It is the first study of Yarkho's contribution to poetics published in Brazil.
\end{abstract}

Palavras-chave: Formalismo Russo; Estudos do verso; Poética quantitativa; Tomachévski; larkhó

Keywords: Russian Formalism; Verse studies; Quantitative poetics; Tomashevsky; Yarkho 


\section{O que é Formalismo Russo?}

* Professor do Department of Slavic, East European and Eurasian Languages and Cultures, University of California, Los Angeles (UCLA), USA; e professor pesquisador do Institute of Humanities, Tallinn University, Estonia. Meu trabalho neste ensaio recebeu 0 apoio do Eesti Teadusagentuur (grant nr PRG319). https://orcid.org/0000-00030153-6598; pilshch@gmail.com
Formalismo é um programa de pesquisa idealizada primeiramente por estudiosos russos, nas décadas de 1910 e 1920, que pertenciam a dois grupos: Sociedade para o Estudo da Linguagem Poética (OPOIAZ) e Círculo Linguístico de Moscou (CLM). Esses grupos não eram, de fato, nem unificados nem consolidados, embora seus membros compartilhassem interesses comuns: todos concebiam a arte (primeiramente a arte verbal e, em seguida, todos os tipos de arte) como um tipo de atividade humana governada mais por suas próprias leis intrínsecas do que predeterminada por condições ideológicas, sociais ou psicológicas. Todos concordavam que o que torna a arte diferente de todo o resto é a forma artística, mas mantinham opiniões diferentes sobre o porquê desta importância e a maneira como esta forma "funciona".

A Rússia do final do século XIX conheceu dois tipos distintos de crítica literária: um deles foi a abordagem positivista das escolas psicológicas e histórico-culturais que se voltaram para o passado e o abordaram de maneira acadêmica. $O$ outro foi o "jornalismo literário", que se voltou para os fenômenos contemporâneos e os abordou ideológica ou esteticamente - a depender da atitude do crítico. No entanto, a literatura modernista e a arte do início do século XX deram origem a novas atitudes. O Simbolismo Russo trouxe a figura do poeta-teórico para o primeiro plano. Poetas como Valéri Briússov e Andrei Biéli almejavam não apenas ser os mestres da versificação, mas também descrever suas poéticas em termos técnicos.

Um modo novo de escrita manteve a atenção dos poetas em questões centradas na questão da forma versífica. Por esta perspectiva, não havia para eles diferenças substanciais entre a poesia contemporânea e a poesia de períodos anteriores. Quando Andrei Biéli evidenciou a dicotomia entre a métrica e o ritmo que constitui a base da versificação sílabo-tônica russa, ele aplicou a análise estatística ao ritmo do verso não só na poesia dos séculos XVIII e XIX, mas também em seus próprios

1 TIHANOV, 2012 
poemas. Biéli tentou explicitar as regras gerais que se aplicam à evolução da poesia russa, partindo do Classicismo do século XVIII até o Simbolismo do XX. Além disso, ao perceber que algumas variedades rítmicas eram muito raras em russo, ele próprio compôs mais versos utilizando este tipo de ritmo. ${ }^{2}$

Quando exatamente o Formalismo Russo surgiu? Ele "nasceu" várias vezes e várias datas de nascimento convencionais podem ser citadas. ${ }^{3} \mathrm{~A}$ mais antiga delas é 23 de dezembro de 1913 (no calendário juliano) - o dia em que um estudante da Universidade de São Petersburgo chamado Víktor Chklóvski, então com vinte anos, deu uma palestra escandalosa chamada "O lugar do Futurismo na história da linguagem" (Место футуризма в истории языка) no cabaré O Cachorro Vira-lata, de São Petersburgo. Porém, nesta época, ainda não existia a associação de acadêmicos "formalistas". A primeira associação foi estabelecida oficialmente em 16 de fevereiro (1 de março no calendário gregoriano) de 1915 e recebeu o nome de Círculo Linguístico de Moscou (Московский лингвистический кружок), doravante CLM. ${ }^{4}$ O objetivo principal do CLM era promover "estudos de linguística, poética, métrica e folclore". ${ }^{5}$ Seu primeiro presidente foi Roman Jakobson (à época um estudante da Universidade de Moscou), que manteve este posto até deixar a Rússia em 1920. As reuniões do CLM tornaram-se regulares em 1919. Entre seus membros mais ativos, de 1919 a 1921, estavam o linguista Grigori Vinokur (secretário do Círculo e seu presidente entre 1922 e 1923), o crítico de esquerda Óssip Brik, o teórico do verso Boris Tomachévski, o medievalista Boris Iarkhó, Víktor Chklóvski, que vinha de Petrogrado para participar dos encontros do CLM, e alguns outros acadêmicos não menos eminentes. ${ }^{6}$

\footnotetext{
2 BIÉLI, 1910, p. 289-300; GASPAROV, 1988.

3 LEVCHENKO, PILSHCHIKOV, 2017, p. 9.

4 JAKOBSON, 1996, p. 361-362.

5 JAKOBSON, 1971 [1965], p. 530.

6 CHAPIR, 2001; PILSHCHIKOV, USTINOV, 2018a, 2018b.
} 
O próximo acontecimento marcante na história do Formalismo é a publicação das duas primeiras coletâneas de ensaios do movimento, editadas por Chklóvski e com certo apoio financeiro de Brik. Os volumes receberam os nomes de Estudos sobre a Teoria da Linguagem Poética (Сборники по теории поэтического языка) e vieram a lume em meados de 1916 e no começo de 1917. Geralmente, acredita-se que os volumes tenham sido publicados pela Sociedade para o Estudo da Linguagem Poética - Общество по изучению поэтического языка (OPOIAZ) -, mas tecnicamente isto não é verdade. A denominação OPOIAZ, hoje mundialmente conhecida, só foi criada mais tarde, em 2 de outubro de 19197, embora "a criação desta nova associação tenha sido decidida" bem antes, em fevereiro de 1917, conforme recorda Roman Jakobson, que foi membro ativo tanto do grupo de Moscou quanto do de Petrogrado, assim como Brik. $^{8}$

Por volta desta época, o grupo de Petrogrado já havia integrado o historiador literário e crítico Boris Eikhenbaum, autor de um artigo cujo título também se tornou emblemático do movimento formalista: "Como é feito 'O Capote', de Gógol" (Как сделана «Шинель» Гоголя, 1919). Esse estudo foi publicado no terceiro volume de Estudos sobre a teoria da linguagem poética, cujo título é Poética (Поэтика). Em 1920 o historiador literário Iúri Tyniánov juntou-se à OPOIAZ e tornou-se o terceiro membro celebrado do "triunvirato" formalista (Chklóvski, Eikhenbaum e Tyniánov). ${ }^{9}$ Tomachévski trocou Moscou por Petrogrado em 1921 e se tornou também um membro da OPOIAZ.

Tanto os formalistas quanto seus contemporâneos estavam completamente conscientes da natureza revolucionária de suas novas teorias. No anúncio sobre a criação da OPOIAZ, publicado no jornal $A$ vida da arte (Жизнь Искусства), em 21 de outubro de 1919, Chklóvski declarou oficialmente: "A revolução na arte tem renovado mentes e libertado a ciência da arte da

7 KRUSÁNOV, 2003, p. 296-297.

8 JAKOBSON, 1971 [1965], p. 529-530.

9 CHÚBIN, 1994, p. 75. 
opressão da tradição. A nova sociedade para o estudo da teoria da linguagem poética nasceu sob o signo da revolução." ${ }^{10}$ No quinto aniversário do CLM, em 29 de fevereiro de 1920, Aleksei Buslaev (um dos cofundadores do CLM e seu presidente entre 1920 e 1922) observou que "a meta principal do Círculo era a revolução metodológica."11 Um artigo abertamente desfavorável, de autoria de Leon Trótski, de título "A escola formalista [no estudo] da poesia e o marxismo" (Формальная школа поэзии и марксизм) - publicado em 1923 no jornal central do partido Bolchevista Pravda e reimpresso no seu livro Literatura e revolução no mesmo ano - começava com um elogio: "A escola formalista é a primeira escola científica da arte. Graças aos esforços de Chklóvski [...] a teoria da arte [...] tem, enfim, passado do estágio da alquimia para a posição da química."12 No mesmo artigo Trótski chama Chklóvski de "o arauto da escola formalista é o primeiro químico da arte".13 Neste clima de cientificismo, Iarkhó queria avançar nos estudos literários da mesma forma que Wilhelm Johannsen havia progredido nos estudos da biologia (veja adiante), mas em sua obra Metodologia de estudos literários exatos (Методология точного литературоведения, 1935-1938) ele se comparou a um acadêmico superior, qual seja, o grande químico do século XVIII Antoine Laurent de Lavoisier: "Situando dados quantitativos e microanálise na base da investigação, eu sugiro apenas que façamos com o estudo da literatura o que Lavoisier fez com a química há um século e meio, e eu não tenho dúvidas de que os resultados não se farão esperar."14

10 CHKLÓVSKI, 1919. No original russo: Революция в искусстве обновила умы и освободила науку об искусстве от гнета традиции. Новое общество изучении теория поэтического языка родилось под знаком революции.

11 Documentos do CLM, 3/№ 4, fol. 81. Citado da Maksim Chapir em seu prefácio a JAKOBSON, 1996, p. 363. No original russo: ...главная задача Кружка \ методологическая революция.

12 TRÓTSKI, 1923, p.119. No original russo: Формальная школа есть первая научная школа искусства. Усилиями Шкловского [...] теория искусства [...] из состояния алхимии переведена наконец на положение химии.

13 Ibidem. No original russo: провозвестник формальной школы, первый химик искусства.

14 IARKHÓ, 2006, p.7; ver: GASPAROV, 1969, p. 506. No original russo: Кладя 
Quem é considerado um formalista e quem não é? Em seu artigo autoexplicativo "A Teoria do Método 'Formal"' (Теория «формального» метода, 1925), Eikhenbaum se diz pertencente à "Escola Formalista", em termos de filiação com a associação que era, de fato, apenas semiformal (trocadilho): "Por 'Formalistas' eu quero me referir [...] apenas àquele grupo de teóricos participantes da 'Sociedade para o Estudo da Linguagem Poética' (OPOIAZ) que começaram a divulgar suas próprias publicações em 1916."15 Este ponto de vista influenciou sobremaneira as interpretações posteriores do Formalismo, apesar dos contínuos esforços de Jakobson para incluir na história do movimento não só apenas a OPOIAZ, mas também o CLM. ${ }^{16}$

Neste artigo, o Formalismo é interpretado conforme a intenção acima de Jakobson. Ou seja, ele procura incluir as produções das duas associações, que juntas são vistas como uma comunidade heterogênea. Formalismo é entendido aqui como um campo teórico comum, criado pelos esforços intelectuais dos membros das duas associações tanto individual quanto coletivamente. A busca teórica de todos eles era guiada pelo(s) mesmo(s) programa(s), embora tendessem a dar respostas diferentes às questões pelas quais estavam todos interessados.

Ainda que sejam muitas e diferentes as ramificações do Formalismo Russo, todas compartilhavam as mesmas premissas:

A literatura (arte verbal) deve ser considerada como um fenômeno per se, e não uma manifestação de fenômenos extraliterários, tal como ocorre com as relações sociais para o marxismo ou com os complexos psicológicos para a teoria freudiana.

\footnotetext{
количественный учет и микроанализ в основу исследования, я только предлагаю сделать для литературоведения то, что полтораста лет тому назад сделал Лавуазье для химии, и не сомневаюсь, что результаты не заставят себя ждать.

15 EIKHENBAUM, 1927 [1925], p. 116, ftn. 1. No original russo: Под «формалистами» я разумею [...] только ту группу теоретиков, которая объединилась В «Обществе изучения поэтического языка» (Опояз) и с 1916 г. начала издавать свои сборники.

16 JAKOBSON, 1971 [1965]; JAKOBSON, 1996. Ver: DMÍTRIEV, 2009 [2007]; DEPRETTO, 2008; SANMARTÍN ORTÍ, 2008.
} 
A forma na arte é o resultado do processamento (da transformação) de seu material. O material da literatura é a linguagem: a literatura é "feita" de linguagem, da mesma forma que a escultura é feita de madeira, argila ou pedra, ao passo que a narrativa é extralinguística: uma mesma história pode ser contada em diferentes linguagens e encarnada em diferentes materiais.

A linguagem poética (artística) é oposta à linguagem cotidiana (prática) e a primeira é definida como uma transformação intencional da segunda.

Essa transformação intencional, que cria uma forma insólita, é a essência de toda arte: em arte, incluindo a verbal, as perguntas 'como?' e 'para quê?' são mais importantes que 'o quê?' e 'por quê?'

Uma vez que a especificidade da arte é o foco na sua própria forma, qualquer análise da arte (literatura incluída) é uma análise formalista.

Portanto, a análise não deve ser impressionista, mas científica. O estudo da literatura precisa tornar-se uma ciência exata.

Embora o programa e os princípios de pesquisa fossem os mesmos, as abordagens eram diferentes. No âmbito do desenvolvimento das teorias formalistas russas de meados dos anos 1910 até final de 1920, várias tendências diferentes com focos e abordagens específicos no que tange ao problema da forma podem ser observados. Os mais importantes para meu propósito neste trabalho foram o Formalismo "morfológico" da OPOIAZ na sua fase inicial, o Formalismo "funcionalista" da OPOIAZ na sua fase tardia e o Formalismo "quantitativo" do CLM. ${ }^{17}$

\section{O que é poética formalista?}

De acordo com Eikhenbaum, o primeiro estágio de desenvolvimento da escola formalista foi caracterizado menos pelo desejo de desenvolver novos métodos de análise literária e

17 Minha tipologia do Formalismo Russo é um pouco diferente e, ao mesmo tempo, complementar às de Aage A. HANSEN-LÖVE (1978) e de Peter STEINER (1984). 
formular uma teoria nova ou uma metodologia do que por uma tentativa de especificar o objeto dos estudos literários. Acadêmicos de outras disciplinas abordavam a literatura de acordo com seus propósitos: psicólogos a examinavam como uma expressão da psique do autor, historiadores das ideias, como uma expressão de uma ideologia particular, e assim por diante. Aleksandr Vesselóvski, um predecessor do Formalismo Russo, ao descrever a situação dos estudos literários no século XIX, afirmou ser a Literatura "uma terra de ninguém" - res nullius. ${ }^{18} \mathrm{O}$ objetivo dos críticos formalistas era "criar uma ciência literária autônoma baseada nas propriedades específicas do material literário", i.e., nas propriedades "que distinguem o material literário de qualquer outro tipo" ${ }^{19} \mathrm{Ou}$, como Jakobson colocou esta questão: "o objeto da literatura não é a literatura, mas a literaturidade, isto é, o que torna uma dada obra uma obra de literatura." ${ }^{20}$

Considerar os limites específicos dos estudos literários como uma disciplina autônoma ("especificação" da literatura, como os formalistas a chamavam) levou a um resultado importante: o procedimento deu origem ao nascimento da "teoria da literatura"21 Um sinônimo possível para esta expressão nova era o velho termo aristotélico "poética", já reavivado e reinterpretado por Aleksandr Vesselóvski. ${ }^{22}$ Contudo, ao contrário da poética histórica de Vesselóvski, a poética formalista era teórica. É sintomático que o compêndio "formalista" de Tomachévski, originalmente publicado em 1925 , leve o título de Teoria da literatura (Poética) [Теория литературы (Поэтика)]. ${ }^{23}$ Além do mais, diferentemente dos escritos sobre poética de Aristóteles, Horácio e Boileau, a poética formalista era descritiva e não prescritiva.

\section{VESSELÓVSKI, 1894, p. 21.}

19 EIKHENBAUM, 1927 [1925], p. 117, 121. No original russo: "создание самостоятельной литературной науки на основе специфических свойств литературного материала", і.е. "особенностей, отличающих его от всякого другого".

20 JAKOBSON, 1921, p.11. No original russo: “...предметом науки о литературе является не литература, а литературность, т.-е. то, что делает данное произведение литературным произведением."

21 TIHANOV, 2019.

22 Ver: KLIGER, MASLOV, 2016.

23 TOMACHÉVSKI, 1923b. 
O objeto dos estudos literários, de acordo com os primeiros estudiosos da OPOIAZ, é a construção da obra artística. Outro termo que os formalistas utilizavam para descrever o tipo de análise que realizavam era "morfologia". No prefácio do seu livro O jovem Tolstói (Молодой Толстой, 1922), Eikhenbaum explicou que "poética" é uma disciplina que se interessa pelo "sistema de procedimentos estilísticos e composicionais" do artista. "Estamos acostumados a chamar tal método de investigação de 'formal', embora eu prefira chamá-lo de 'morfológico' para diferenciá-lo de outros (psicológico, sociológico etc.) em que o objeto de investigação não é a obra de arte propriamente, mas o que ela 'reflete' na opinião do investigador." ${ }^{24}$ Assim como na linguística e na biologia, uma análise morfológica de um texto literário revela suas partes constituintes e explicita seu funcionamento. O próximo passo lógico no desenvolvimento de uma abordagem deste tipo foi a transformação do formalismo "morfológico" dos finais de 1910 e começos de 1920 no formalismo "funcionalista" do final dos anos de 1920. Essas versões da teoria literária formalista - o formalismo "morfológico" e o "funcionalista" - foram canonizadas na monografia de Victor Erlich, Russian Formalism: history - doctrine ${ }^{25}$ e também na antologia de textos dos formalistas que Tzvetan Todorov organizou e traduziu para o francês, significativamente chamada Théorie de la littérature.$^{26} \mathrm{O}$ mesmo título foi utilizado antes por Theory of Literature de René Wellek e Austin Warren, ${ }^{27}$ obra que incorpora e ambienta muitos conceitos do Formalismo Russo e do Estruturalismo Tcheco.

Em 2011, Franco Moretti e Matthew Jockers, cujos nomes vêm imediatamente à mente quando se pensa em Humanida-

\footnotetext{
24 EIKHENBAUM, 1922b, p. 8. No original russo: “... о системе его стилистических и композиционных приемов. Такой метод у нас принято называть «формальным» - я бы охотнее назвал его морфологическим, в отличие от других (психологического, социологического и т.д.), при которых предметом исследования служит не само художественное произведение, а то, «отражением» чего является оно по мнению исследователя."

25 ERLICH, 1955 (1965).

26 TODOROV, 1965.

27 WELLEK, WARREN, 1949 (1956, 1963).
} 
des Digitais, chamaram o método de pesquisa desenvolvido por eles de "formalismo quantitativo". O manifesto do Laboratório Literário de Stanford, cofundado por Moretti em 2010, foi intitulado Formalismo Quantitativo: um experimento e foi assinado por Jockers, Moretti e outros coautores. ${ }^{28}$ Assim, por um lado, eles explicitaram qual era a fonte principal na qual se inspiraram: o Formalismo Russo; por outro, enfatizaram a principal diferença entre os dois movimentos. O grupo chamou a versão por eles desenvolvida de Formalismo "quantitativo", em contraste com o Formalismo Russo, que, na opinião deles, seria qualitativo devido ao fato de o movimento estudar as diferenças qualitativas (e não quantitativas) entre estruturas literárias. De fato, a análise do texto poético, que os próprios formalistas chamavam "morfológica" (e a próxima geração de pesquisadores chamou de estrutural ou estruturo-funcional) estava no centro do programa formalista. No entanto, a tese em torno da novidade do formalismo quantitativo é apenas parcialmente verdadeira. Ela só faz sentido se, seguindo Eikhenbaum, restringirmos o "Formalismo" exclusivamente ao que foi produzido em parte no âmbito da OPOIAZ, já canonizada na Europa e na América do Norte.

Em um outro ensaio, eu chamei de "qualitativas" as abordagens "morfológica" e "funcionalista" desenvolvidas pelos formalistas em oposição ao formalismo "quantitativo", representado por vários estudiosos do CLM. ${ }^{29}$ É hora de vermos de perto o aspecto quantitativo do Formalismo Russo, que é bem menos conhecida dos leitores, especialmente fora da Rússia.

\section{O que é poética quantitativa?}

Ao contrário da OPOIAZ, com seu foco no objeto - mais do que nos métodos - dos estudos literários, o CLM buscou "elaborar um novo método de análise linguística com referência particular às diversas funções da linguagem, especialmente

28 ALLISON, HEUSER, JOCKERS, MORETTI, WITMORE, 2011.

29 PILSHCHIKOV, 2018. Ver também: DEPRETTO, 2018. 
à função poética". ${ }^{30} \mathrm{Um}$ dos meios para encontrar uma abordagem uniforme no estudo de todas as formas de arte verbal foi o uso dos métodos matemático-estatísticos, que já havia provado sua eficácia na biologia contemporânea. Se a biologia - anteriormente uma disciplina puramente descritiva e classificatória - havia se tornado uma 'ciência exata', por que então a linguística e a poética não poderiam fazer o mesmo ou ao menos dar os primeiros passos para este objetivo nobre? 0 aspecto da poesia a que esses métodos eram mais empregados era o da versificação. A razão disso era que "os elementos que constituem o nível fônico na estrutura da obra literária (sílabas, acentos, duração) se mostravam mais fáceis de serem isolados e contados do que os elementos dos níveis mais elevados (figuras de estilo, motivos de enredo etc.)". ${ }^{31}$

Em 1919, dois estudiosos que anteriormente (e de maneira independente) haviam desenvolvido alguns métodos estatísticos para o estudo do verso - Boris Tomachévski e Boris Iarkhó - começaram a frequentar regularmente os encontros do CLM. No dia 21 de junho de 1919, atendendo a uma proposta de Jakobson, os dois foram eleitos membros plenos do Círculo. ${ }^{32}$ Deve ser notado uma vez mais que Tomachévski, comumente lembrado como um acadêmico de Petrogrado e membro da OPOIAZ, produziu uma parte significativa de sua pesquisa sobre o verso russo em Moscou, onde viveu de 1918 até o final de 1920 (depois de retornar das frentes da Primeira Guerra Mundial), e os apresentou nos encontros no CLM ${ }^{33}$ Os trabalhos de Tomachévski junto à OPOIAZ pertencem ao período seguinte (1922-1927). Seus estudos quantitativos do verso do período moscovita foram publicados numa coletânea individual intitulada Sobre o verso (О стихе) somente em 1929, em Lenin-

30 JAKOBSON, 1971 [1965], p. 531.

31 GASPAROV, 1974, p. 18 (Esse artigo também está disponível em traduções italiana e inglesa). No original russo: “...элементы звукового уровня в структуре литературного произведения (слоги, ударения, долготы) значительно легче поддавались выделению и подсчету, чем элементы высших уровней (стилистические фигуры, сюжетные мотивы и пр.)."

32 Documentos do CLM, 2/№ II.10, fol. 61.

33 FLEISHMAN, 1977. 
grado. Para agravar o equívoco, a antologia de Todorov inclui somente as seções de Sobre o verso que não contêm cálculos, diagramas e nem tabelas. ${ }^{34}$

Essas novas formas de abordagem se baseavam nas descobertas de acadêmicos empírico-positivistas alemães do século XIX no campo da filologia clássica, tais como Moritz Wilhelm Drobisch e Arthur Ludwich, que haviam utilizado dados estatísticos para atribuir e datar os hexâmetros gregos e romanos antigos (a distribuição dos pés dactílicos e espondaicos). ${ }^{35}$ Eles também foram diretamente influenciados para as então mais recentes descobertas de Andrei Biéli, que aplicou métodos estatísticos na análise do ritmo do verso silábico-acentual russo (a distribuição dos pés dissilábicos com e sem uma sílaba tônica).$^{36}$ Contudo, os formalistas de Moscou consideravam as tentativas de seus predecessores inconsistentes e autocontraditórias, já os seus dados, incompletos e aproximados. ${ }^{37}$

Num encontro do CLM, ocorrido em 8 junho de 1919, Tomachévski apresentou a comunicação "Sobre o pentâmetro iâmbico de Púchkin" (О пятистопном ямбе Пушкина). Este estudo foi publicado mais tarde, em 1923, e reimpresso numa versão reduzida em Sobre o verso. ${ }^{38}$ Nele, Tomachévski compara as características estatísticas do ritmo do pentâmetro iâmbico de Aleksandr Púchkin com o de outros poetas russos e com outros metros europeus de mesmo volume silábico (com o hendecassílabo italiano, com o decassílabo francês, com o pentâmetro iâmbico silábico-acentual inglês e alemão). Em particular, isso permitiu a Tomachévski revelar a influência do ritmo do decassílabo francês sobre o pentâmetro iâmbico do Príncipe Piotr Viázemski de 1821-1825 - os anos em que Viázemski, um dos melhores amigos de Púchkin, esteve traduzindo os epigramas de Jean-Baptiste Rousseau.

34 Ver: TODOROV, 1965, p. 154-169.

35 Ver: GASPAROV, 1997, p. 234.

36 GASPAROV, 1974, p. 20-21.

37 Ver: PILSHCHIKOV, USTINOV, 2020.

38 TOMACHÉVSKI, 1923a; TOMACHÉVSKI, 1929, p. 138-253. 
Neste e em outros estudos do verso dos finais de 1910, Tomachévski também se valeu de um método estatístico de sua autoria. Tal método envolvia a comparação entre indicadores teóricos e empíricos ${ }^{39} \mathrm{~A}$ frequência teórica de ocorrência de um verso contendo palavras de estrutura acentual particular resulta da frequência dessas palavras nas obras de um dado autor (ou na prosa contemporânea - Tomachévski deixou esta questão em aberto). Para estabelecer as conclusões sobre o ritmo dos versos reais, é necessário "comparar essa ocorrência de tipo teórico com uma de ordem real" ${ }^{40}$ Esse método (mais tarde alterado por acadêmicos, incluindo o proeminente teórico do verso Kiril Taranóvski a o matemático Andrei Kolmogórov - provavelmente o mais destacado matemático soviético do século 20) foi batizado de "O método linguístico-estatístico russo para o estudo do ritmo poético". ${ }^{41} \mathrm{Em} 1960$, Jakobson declarou a abordagem prosódica de Tomachévski "um exemplo do mais extenso e talvez, até recentemente, o mais espetacular vínculo entre linguística, em particular o estudo da linguagem poética, de um lado, e a análise matemática de processos estocásticos, de outro." Esta abordagem "forneceu pistas surpreendentes para a métrica descritiva, histórica, comparativa e geral sobre uma base científica." ${ }^{42}$

Menos consagrado é o reconhecimento de Jakobson no seu livro sobre a teoria do verso, Sobre o verso tcheco: principalmente em comparação com o verso russo (О чешском стихе: преимущественно в сопоставлении с русским, 1923). О livro foi impresso em Berlim, e em parte das cópias as siglas

39 GASPAROV, 1974, p. 21.

40 TOMACHÉVSKI, 1923a, p. 40. No original russo: "сравнить теоретическую встречаемость с действительной."

41 BAILEY, 1979.

42 JAKOBSON, 1971 [1960], p. 579. Depois de Sobre o verso (TOMACHÉVSKI, 1929) e da sexta edição de Teoria da Literatura (TOMACHÉVSKI, 1931), Tomachévski abandonou os estudos do verso e de poética (ver: SEEMANN, 1986) e focou na textologia e biografia de Aleksandr Púchkin ("textologia" foi um termo cunhado por ele nos anos de 1920), e também na pesquisa dos interesses de Púchkin pela literatura francesa. Tomachévski escapou dos expurgos antiformalistas, mas seus trabalhos no campo da Literatura Comparada foram oficialmente condenados durante a campanha anticomparatista de 1949. Ele retornou aos estudos do verso somente no final de sua vida (ele faleceu em 1957). 
"OPOIAZ - CLM" apareciam como responsáveis pela edição: "Os debates no Círculo Linguístico de Moscou, especialmente as contribuições de O.M. Brik e B.V. Tomachévski sobre o verso russo, pela primeira vez explicitaram nitidamente os problemas do estudo do ritmo para mim". ${ }^{43}$ Nos seus estudos sobre a poesia tcheca, publicados na década de 1930, Jakobson se valeu dos métodos de Tomachévski e os desenvolveu. No artigo dedicado à versificação do poeta romântico tardio Karel Jaromír Erben, Jakobson calculou as frequências de sílabas tônicas nos versos isossilábicos para provar a natureza silábico-acentual da poesia de Erben, a qual havia sido negada pelos primeiros estudos do autor. Todavia, o iambo de Erben é menos rigoroso que o iambo dos neoclassicistas tchecos. Para criar uma forma mais flexível de iambo, Erben se inspirou no tcheco antigo e na poesia folclórica. Neste sentido, os iambos de Erben são próximos aos do poeta romântico Karel Hynek Mácha"4 (Jakobson os reuniu sob o conceito comum de "iambo romântico tcheco").45

No seu artigo "Para uma descrição do verso de Mácha", Jakobson parte de uma análise formal em direção a uma análise semântica. ${ }^{46}$ No poema "Maio" (Máj, 1836), de Mácha, $89 \%$ dos versos são iâmbicos; iambo é o oposto do troqueu - a medida tradicional e mais recorrente na poesia tcheca. Para demonstrar as diferenças rítmicas entre esses metros, Jakobson, apoiando-se nas ideias de Tomachévski, analisou os padrões de alternância entre ictos ${ }^{47}$ "fortes" (mais frequentemente tônicos) e "fracos" (menos frequentemente tônicos). No tetrâmetro trocaico de Mácha, uma tendência para uma "dissimi-

43 JAKOBSON, 1923, p.6. No original russo: "Дебаты Московского Лингвистического Кружка, особенно доклады О.М. Брика и Б.В. Томашевского о русском стихе, впервые отчетливо осветили мне проблемы научной ритмики."

44 Embora as paroxítonas terminadas em "a" não recebam acento gráfico em português, optou-se aqui pelo diacrítico para marcar a duração longa da vogal "a" conforme pronúncia tcheca do nome do poeta. (Nota do tradutor)

45 JAKOBSON, 1935. Essa generalização foi mais tarde contestada pelo acadêmico tcheco Miroslav Červenka (ver a nota 47).

46 JAKOBSON, 1938. (Mais conhecida na tradução inglesa de Peter e Wendy Steiner, publicada em Selected Writings de Jakobson: JAKOBSON, 1979).

47 Ictos são as sílabas marcadas em um padrão métrico. 
lação progressiva" se revela: o primeiro icto é o mais forte e os ictos pares são mais fracos que os ímpares. No tetrâmetro iâmbico de Mácha, acontece exatamente o oposto: o primeiro icto é o mais fraco e cada um dos ictos seguintes é mais frequentemente tônico que os anteriores. ${ }^{48}$ Jakobson oferece uma descrição similar dos iambos e dos troqueus de Mácha de outras extensões métricas. Esse tipo de análise foi mais tarde chamado de análise rítmica "vertical" ou de análise do ritmo "secundário". O ritmo "secundário" dos metros binários russos foi investigado por Kiril Taranóvski, Mikhail Gasparov, James Bailey, Mikhail Lotman, Maksim Chapir, entre outros.

Desta forma, Jakobson procede rumo a uma análise das funções semânticas dos metros no poema de Mácha. De um lado, um poeta pode usar as mesmas formas métricas em poemas que sejam tematicamente e emocionalmente dissimilares. Por outro lado, numa dada tradição poética, pode haver uma tendência para associar cada metro a uma esfera semântica particular e com um colorido emocional (esse fenômeno foi chamado mais tarde de "auréola semântica [ou halo semântico] de um metro"). Essa ideia remonta à observação de Óssip Brik durante os debates em torno de seu estudo "Sobre o ritmo do verso", realizados durante o encontro do CLM de 1 de junho de 1919 e presidido por Jakobson (veja adiante). Brik levantou a questão da semântica do metro e demonstrou a conexão entre o pentâmetro trocaico russo e o "tema do seguir o caminho". Jakobson usou esses exemplos em seu artigo sobre Mácha. ${ }^{49} \mathrm{Um}$ amplo conjunto de investigações nesta área foi subsequentemente empreendido por Kiril Taranóvski (normalmente considerado o iniciador deste tópico de pesquisa), Mihhail Lotman, Mikhail Gasparov e Michael Wachtel.

Boris Iarkhó foi além de Tomachévski e Jakobson: ele estava convencido da possibilidade de uma quantificação total

48 No iambo tetrâmetro de Erben, porém, o último icto não é o mais forte. Essa é uma das razões da ressalva de Červenka contra a afirmação de Jakobson de que os versos de Mácha e de Erben eram do mesmo tipo (ČERVENKA, 1973, p. 84-85; cf. ČERVENKA, 1981, p. 266269 e 271-278, notas 6-7).

49 Ver: CHAPIR, 1991; PILSHCHIKOV, 2017b: 169. 
da poética. ${ }^{50}$ Além da abordagem probabilístico-estatística do verso (em particular, ele pesquisou poesia latina medieval, opondo seus métodos estatísticos aos de Meyer aus Speyer), Iarkhó ampliou o uso de métodos quantitativos para todos os domínios da forma artística - som, gramática e sentido. Seu Metodologia de estudos literários exatos e seus estudos de gêneros dramáticos em perspectivas sincrônicas e diacrônicas são de primeira importância. Esses trabalhos foram concluídos entre o final dos anos de 1920 e o final de 1930 - os mais importantes foram escritos no exílio em Omsk entre 1935 e 1938 - e publicados muito mais tarde, entre 1997 e $2006 .{ }^{51}$

Iarkhó especificou as características da tragédia e da comédia utilizando para tal parâmetros formais e quantitativos como o número completo de personagens (dramatis personae); o número de personagens que falam em cada cena e o desvio-padrão do número médio de personagens que falam em todas as cenas; o número de cenas na peça (a medida de mobilidade da ação); o comprimento médio dos comentários dos personagens que falam e a porcentagem de versos divididos entre os comentários diferentes (as medidas de mobilidade e de coerência do diálogo); e similares. A proporção desses elementos em peças diferentes diverge. A história de um gênero pode ser descrita como uma evolução de suas características e grupos de características. As diferenças entre tendências literárias podem ser descritas como a diferença nas proporções de características particulares e de grupos de características. Os cálculos de Iarkhó possibilitaram-lhe demonstrar que a história da tragédia de cinco atos em verso pode ser dividida em 4 períodos (clássico antigo, clássico tardio, romântico antigo e

50 GASPAROV, 1969 (esse artigo também está disponível em traduções para o inglês e para o francês); MARGOLIN, 1979.

51 Depois da supressão do Formalismo em 1930, larkhó encontrou refúgio temporário em traduções poéticas antes de se convencer do caso falsificado dos "Lexicógrafos alemães". Ele foi condenado à prisão em Moscou e exilado em Omsk, na Sibéria, enquanto seu colega e oponente de longa data Gustav Chpet, também um ex-membro do CLM, depois de ser exilado em Tomsk (também na Sibéria), foi assassinado a tiros em 1937. Em 1940, larkhó foi autorizado a ir para Kursk, na parte europeia da Rússia, onde se tornou professor no instituto pedagógico local. Depois da invasão alemã, em 1941, ele foi levado para Sarápul na Udmúrtia, onde morreu de tuberculose miliar em 1942. Veja um esboço biográfico conciso, porém abrangente, de Maksim Chapir e Marína Akímova em IARKHÓ, 2006, p. vii-xxxii. 
romântico tardio) e que é possível determinar os limites entre esses períodos..$^{52}$ Enquanto isso, quando Iarkhó comparou dois gêneros que coexistem num dado período de tempo (Iarkhó focou as tragédias e comédias de Pierre Corneille), ele pôde estabelecer com precisão as diferenças entre ambos. Iarkhó estabeleceu as características quantificáveis que distinguem um gênero de outro, calculou as proporções de suas combinações em vários textos e localizou gêneros intermediários (tragicomédias) nas escalas entre uma tragédia prototípica e uma comédia prototípica. ${ }^{53}$

De acordo com Iarkhó, há três domínios de formas poéticas: Fônica (formas sonoras: ritmo e eufonia);

Estilística (formas de linguagem, incluindo formas gramaticais e retóricas);

Eidologia, ou iconologia, ou poética stricto sensu (formas conceituais e emocionais, assim como imagens, motivos e enredos).

O quarto domínio da forma, a composição, é de natureza combinatória e descreve a inter-relação entre os níveis ou entre seus elementos. ${ }^{54}$

Iarkhó apresentou exemplos de estudos estatísticos para todos os domínios anteriormente mencionados. O mais impressionante talvez seja sua abordagem da eidologia - um exemplo é a análise estatístico-comparativa da concepção ideológica de La chanson de Roland. Iarkhó resolveu uma disputa entre duas teorias predominantes sobre a Chanson (a antiga, que defendia que a Chanson foi composta em ambiente militar, e a mais recente, que advogava a favor de uma atmosfera clerical). Iarkhó confirmou a teoria mais antiga com dados estatísticos, mostrando que os tópicos cristãos ocupavam muito menos espaço em La chanson de Roland do que em uma obra clerical de mesmo enredo (Rolandslied, de Konrad der Pfaffe) e, portanto, a ideologia da versão original era secular e cavaleiresca..$^{55}$

52 IARKHÓ, 1997; republicado em IARKHÓ, 2006, p. 550-607. Tradução inglesa: IARKHÓ, 2019.

53 IARKHÓ, 1999/2000; republicado em IARKHÓ, 2006, p. 403-449.

54 IARKHÓ, 1927. Tradução inglesa: IARKHÓ, 2016.

55 Ver: GASPAROV, 1969, p. 508-509. 
Iarkhó estava claramente inspirado na aplicação da estatística na biologia. Ele escreveu, referindo-se a Wilhelm Johannsen, um eminente botânico dinamarquês que desenvolveu métodos de bioestatística para o estudo da variabilidade genética:

Embora a biologia não possa ser considerada uma "ciência exata" na mesma medida que as ciências que se baseiam na matemática são, ela, assim como o estudo da literatura, possui um alto nível de precisão e de demonstrabilidade, nível que [...] é uma meta desejável e alcançável [...] para nós. Portanto, se eu falo a respeito de um "estudo exato da literatura", eu quero dizer com isso o mesmo que Johannsen, que intitulou seu livro de Elementos de estudos exatos sobre hereditariedade [Elemente der exakten Erblichkeitslehre]". ${ }^{56}$

René Wellek descreveu os membros da OPOIAZ como "positivistas com um ideal de pesquisa literário-científico". ${ }^{57}$ Essa característica parece mais uma descrição de Iarkhó do que dos formalistas de Petrogrado, embora alguns de seus primeiros pronunciamentos sobre as leis sonoras da linguagem poética (por exemplo, as de Lev Jakubínski) pareçam de fato positivistas.

Podemos então incluir Iarkhó na escola formalista? Embora a resposta de Eikhenbaum fosse "não", o próprio Iarkhó diria que "sim". Numa carta a Víktor Jirmúnski de 8 de novembro de 1919, Iarkhó inequivocamente se autodeclarou "um advogado do 'Método Formal' e um 'Formalista'." ${ }^{58}$ Ele descreveu os princípios básicos da análise literária que devem preceder quaisquer operações estatísticas em um artigo intitulado

56 IARKHÓ, 2006, p.29-30. No original russo: “...хотя и нельзя назвать биологические дисциплины такими же «точными науками», как математические, но по сравнению с литературоведением они обладают такой степенью точности и доказательности, которая [...] является для нас заманчивой и [...] достижимой целью. Поэтому, если я говорю о «точном литературоведении», то лишь в том смысле, в каком Иогансен озаглавил свою книгу: «Введение в точное учение о наследственности»." A propósito, é justamente neste livro, publicado em 1909, que Johannsen introduziu o termo gene. É interessante observar que a expressão "gênero como um gene" é encontrada em um dos cadernos de lúri Tyniánov (TÓDDES, TCHUDAKÓV, TCHUDAKÓVA, 1977, p. 511).

57 WELLEK, 1961, p. 106.

58 IARKHÓ, 2006, p. xxvi ftn. 34. 
"Fundamentos elementares da Análise Formal" (Простейшие основания формального анализа, 1927). ${ }^{59}$ Além disso, Iarkhó tem sido definido recentemente como um "ultra formalista". ${ }^{60}$ Essa definição tem tanto peso quanto a exclusão categórica de Eikhenbaum. ${ }^{61}$

Ao mesmo tempo, o próprio Iarkhó opôs seu método ao da OPOIAZ enquanto método quantitativo que se opunha ao qualitativo. Essa oposição está posta de maneira mais evidente na discussão sobre o conceito de "dominante". No decorrer das palestras sobre o Formalismo Russo, que Jakobson apresentou em tcheco na Universidade de Brno em 1935, ele dedicou uma palestra inteira à noção de "dominante" e, mais tarde, publicou-a em inglês, ${ }^{62}$ francês e em russo. Jakobson descreve a noção de dominante como "um dos conceitos mais cruciais e produtivos elaborados pela teoria formalista russa", em seguida dá sua definição do termo: "Dominante pode ser definido como o componente focalizante de uma obra de arte: algo que governa, determina e transforma os componentes remanescentes. É a dominante que garante a integridade da estrutura." ${ }^{63}$

O conceito de "dominante" (доминанта) foi introduzido por Boris Eikhenbaum e Iúri Tyniánov, que o tomaram emprestado do esteta alemão Broder Christiansen e o reinterpretaram. ${ }^{64}$ Eikhenbaum foi o primeiro a usar o termo em A melódica do verso lírico russo (Мелодика русского лирического стиха, 1922), com uma referência direta a Christiansen. ${ }^{65}$ Para o es-

59 Ver nota 55.

60 CARPI, 2006, p. 145.

61 POLILOVA, 2011.

62 In MATĚJKA, POMORSKA, 1971, p. $82-87$ (traduzido por Herbert Eagle).

63 Ibidem, p. 82. No original tcheco: "Definuji dominantu jako směrodatnou složku díla, složku, která ovládá, určuje, přetvořuje ostatní složky díla. Právě dominanta zaručuje celistvost struktury" (JAKOBSON, 2005 [1935], p. 87).

64 Ver: ERLICH, 1965, p. 199-200, 212-215; HANSEN-LÖVE, 1978, p. 314-319; STEINER, 1984, p. 104-106; DAVYDOV, 1985; HANSEN-LÖVE, 1986.

65 EIKHENBAUM, 1922a, p. 9. Os formalistas podem ter lido Philosophie der Kunst (Philosophy of Art), de Christiansen, no original alemão (1909) ou mesmo em tradução russa feita pelo filósofo Georgi Fedótov (1911). 
teta, o objeto estético é criado graças à síntese perceptiva de várias impressões sobre a obra. Quatro fatores (Faktoren) participam desta síntese: $\mathrm{o}$ assunto (Gegenstand), a forma (Form), o material (Stoff) e a técnica (Methode/Hantierung). ${ }^{66} \mathrm{Nem}$ todos são iguais - um deles ou um grupo deles geralmente predomina, i.e., "avança para o primeiro plano e assume a liderança". ${ }^{67}$ Isto é chamado de "die Dominante". De acordo com O problema da linguagem poética (Проблема стихотворного языка, 1924), de Tyniánov, todos os fatores envolvidos na criação de uma obra artística são formais e a interação entre eles cria a semântica da poesia. A dominante - também chamada de "fator construtivo" - subordina os outros fatores a si mesma. Contudo, ela não os harmoniza, como Christiansen pensava, mas os "deforma" (i.e., transforma) ${ }^{68}$ Desta forma, Tyniánov acabou modificando o par terminológico "fatores//dominante" que já se encontrava em Christiansen.

Contudo, a teoria sobre a noção de "dominante" não era propriedade exclusiva dos formalistas de Petrogrado. Iarkhó também dedicou muitas páginas de seu Metodologia a esse conceito. Mas, diferentemente dos estudiosos da OPOIAZ, que interpretaram o conceito numa chave funcionalista e axiológica, Iarkhó, em suas próprias palavras, "reinterpretou o conceito de dominante numa base quantitativa" ${ }^{69}$ Para ele, a validade estética de qualquer elemento em qualquer nível da obra artística é determinada não tanto pela sua particularidade estrutural, quanto pela sua particularidade quantitativa. Para ser válido esteticamente, o elemento deve ser percebido como incomum (esta é uma tese compartilhada por todos os formalistas). Em termos quantitativos, "incomum" quer dizer "excepcionalmente frequente" ou "excepcionalmente infrequente". Com sua admiração pela biologia, Iarkhó também se inspirou nas implicações biológicas do termo dominante, cha-

66 CHRISTIANSEN, 1909, p. 241-251; CHRISTIANSEN, 1911, p. 203-211.

67 CHRISTIANSEN, 1909, p. 241; CHRISTIANSEN, 1911, p. 204. No original alemão: "...sich in den Vordergrund schiebt und die Führung übernimmt."

68 TYNIÁNOV, 1924

69 IARKHÓ, 2006, p. 107. No original russo: “...перевел вопрос о доминанте на количественную базу." 
mando a atenção para os traços dominantes e recessivos dos gêneros e das obras literárias.

\section{A poética estrutural e quantitativa}

Embora Tomachévski e Iarkhó sejam categorizados aqui como "formalistas quantitativos", há uma diferença importante entre suas metodologias. Eles calcularam coisas diferentes e de diferentes maneiras. ${ }^{70}$ Iarkhó - assim como seus predecessores alemães -, no geral, conta qualquer coisa e procede indutivamente. ${ }^{71}$ Ele descobre padrões e anomalias, o detalhamento dessas anomalias acaba por revelar novos padrões e assim por diante. Já Tomachévski procede dedutivamente da teoria do metro e do ritmo, que ele verifica e refina. No final, essas diferenças podem ser reduzidas a dois tipos de empiricismo - o de tipo baconiano (generalizações indutivas baseadas em observação imparcial de experiência sensória) vs o cartesiano (dedução de hipóteses a partir de princípios primários, com verificação subsequente e/ou refinamento). Essa também é uma das principais diferenças entre o positivismo do século XIX e o pós-positivismo do século XX. ${ }^{72}$ Visto por este ângulo, Tomachévski está mais próximo de formalistas "qualitativos" como Jirmúnski do que de Iarkhó. ${ }^{73}$ Ao contrário dos artigos exploratórios de Tomachévski, seu tratado sobre a prosódia russa e a seção de seu compêndio de poética dedicado à métrica comparativa não contém cálculos. ${ }^{74}$

70 Como indicado por Mihhail Lotman em e-mail de 19 de junho de 2018 ao autor deste artigo. A oposição a seguir entre o empirismo baconiano e o cartesiano (aplicados a larkhó e a Tomachévski) pertence a Lotman.

71 Embora "dedutivamente em um nível diferente", como Galin Tihanov escreveu em e-mail de 30 de junho de 2019 ao autor deste artigo: "no sentido de aceitar, antes de iniciar sua análise quantitativa, as premissas advindas de conteúdos, de ideias e de ideologia".

72 Como enfatizado por Peter Steiner em uma comunicação pessoal ao autor deste ensaio em 5 de agosto de 2019 .

73 Um fato revelador é que em seu livro Rima, sua história e teoria (1923), Jirmúnski usou muito as estatísticas para substanciar suas declarações, mas não as publicou (ver: JIRMÚNSKI, 1923, p. 308-310; cf.: GASPAROV, 1974, p. 32).

74 TOMACHÉVSKI, 1923b; TOMACHÉVSKI, 1925, p. 72-132. 
Iarkhó também insistiu na necessidade de uma análise qualitativa ("morfológica") que poderia tanto preceder como suceder à análise quantitativa. Na verdade, a pré-condição para a aplicação da estatística é que haja uma análise filológica acurada da estrutura textual. Por um lado, as únicas características de um texto adequadas à interpretação crítica são aquelas obtidas a partir do resultado de um exame estatístico objetivo. Por outro lado, nas palavras do próprio Iarkhó, "nenhuma característica estatística pode ser introduzida sem uma análise morfológica, isto é, sem o exame dos fenômenos literários reais que ela reflete". ${ }^{75}$

A teoria formalista do verso não é puramente quantitativa - ela combina abordagens quantitativas e qualitativas. Várias ideias inovadoras foram formuladas inicialmente por Óssip Brik, cujo papel como inventor pode ser comparado ao de Chklóvski. ${ }^{76}$ Mencionarei neste ponto apenas duas ideias de Brik que têm influência formativa sobre o desenvolvimento da teoria formalista do verso. ${ }^{77}$

No encontro do CLM, ocorrido em 1 de junho de 1919, Brik apresentou um estudo intitulado "Sobre o ritmo do verso" e discutiu esta mesma questão em uma reunião da OPOIAZ de 1920, com uma comunicação intitulada "Sobre as figuras rítmico- sintáticas" ${ }^{78} \mathrm{Na}$ sequência, ele começou (mas nunca concluiu) sua monografia Ritmo e sintaxe (Ритм и синтаксис), da qual foram retirados alguns excertos para serem publicados na revista Nova Frente de Esquerda das Artes (Новый Лeф, 1927), depois da dissolução da OPOIAZ e do CLM. ${ }^{79}$ Estes estudos inovadores de Brik despertaram questões de como o metro e o ritmo estão ligados ao vocabulário, à gramática e à

75 IARKHÓ, 2006, p. 7. No original russo: "...ни одна статистическая величина не вводится без морфологического анализа, т.е. без проверки того, какие реальные литературные явления она отражает."

76 JAKOBSON, 1964.

77 Para maiores detalhes, ver: PILSHCHIKOV, 2011, p. 100-101; PILSHCHIKOV, 2015, p. 333334.

78 Ver: PILSHCHIKOV, 2017b.

79 BRIK, 1927. Várias seções foram reimpressas em tradução inglesa em MATĚJKA, POMORSKA, 1971, p. 117-125. 
sintaxe. Um aspecto desse problema - qual seja: a entonação como uma inter-relação entre segmentos sintáticos e poéticos - foi criteriosamente investigado no livro de Eikhenbaum, $A$ melódica do verso lírico russo (1922), que, à feição de fonte de inspiração, começa com uma referência explicita à comunicação que Brik apresentou à reunião da OPOIAZ em $1920 .{ }^{80}$ Eis como Eikhenbaum descreveu o novo domínio dos estudos do verso:

A frase poética não é um fenômeno sintático em geral, mas um fenômeno rítmico-sintático. [...] A sintaxe, que se atualiza na [entonação], está articulada, no verso, não em divisões semânticos, mas em divisões rítmicas: às vezes [o segmento sintático] coincide com o rítmico (um verso = uma frase), mas, às vezes, ela os ultrapassa (enjambement). ${ }^{81}$

Partindo da dicotomia entre ritmo e metro, conforme proposta por Andrei Biéli, ${ }^{82}$ Tomachévski e Jirmúnski desenvolveram o conceito de "impulso rítmico" apresentado por Brik. Eis o que escreve Tomachévski em seu tratado sobre a prosódia russa, Versificação russa: Métrica (Русское стихосложение: Метрика):

Quando o poeta inicialmente concebe um poema, ele adota um esquema métrico que ele sente como um certo tipo de desenho rítmico-melódico, dentro do qual as palavras são "inseridas". Encarnando-se na palavra, o impulso rítmico encontra expressão no ritmo concreto de versos particulares. [...] 0 ouvinte percebe o ritmo na ordem inversa. Primeiro ele é confrontado com o ritmo concreto do verso. Em seguida, sob a impressão da repetição da linha rítmica, devido à sua percepção da série dos versos, o ouvinte capta o impulso rítmico [...]. Em um grau ainda mais elevado de abstração da estrutura rítmica, ele descobre também o esquema métrico que é revelado pela escanção. ${ }^{83}$

80 EIKHENBAUM, 1922a, p. 5-6 ftn. 1. See HANSEN-LÖVE, 1978, p.310-314.

81 EIKHENBAUM, 1922a, p. 6. No original russo: "Стихотворная фраза есть явление несинтаксическое вообще, а явление ритмико-синтаксическое. [...] Синтаксис, реализующий [интонацию], членится в стихе не по смысловым делениям, а по ритмическим, то совпадая с ними (строка = фразе), то преодолевая их (enjambement)." 82 BELYI, 1910, p. 396.

83 TOMACHÉVSKI, 1923b, p. 83. No original russo: "Поэт, замышляя стихотворение, 
O conceito de impulso rítmico descreve uma norma estocástica, não determinística: ${ }^{84}$ ela se manifesta na estatística das formas rítmicas. ${ }^{85}$ Neste ponto, as abordagens qualitativas e quantitativas tornam a se encontrar.

Formalismo "quantitativo" pode também ser definido como um "formalismo orientado a dados" ${ }^{86}$ Sua principal realização foi a criação de uma teoria estatístico-estocástica e de uma poética quantitativa. Mas, contrariamente ao formalismo "qualitativo", o impulso básico dos "quantitativistas" era metodológico e não teórico. Hoje tendemos a concordar com os "insights" de Tyniánov, mas preferimos usar os métodos de Tomachévski e de Iarkhó para obter resultados novos. Os avanços mais recentes dos métodos computacionais, formais e quantitativos na análise de textos literários têm despertado interesse na quantificação dos estudos literários. Com o advento das tecnologias da informação e da comunicação, e também das Humanidades Digitais, como o aprendizado de máquina e as redes neurais artificiais, alguns dos projetos de viés estatístico que pareciam abrangentes demais e demasiadamente trabalhosos oitenta ou mesmo vinte anos atrás - como o programa de Iarkhó para o estudo estatístico sincrônico-diacrônico de todos os níveis e aspectos dos textos literários - hoje se mostram totalmente ao nosso alcance. Iarkhó chamou este tipo de abordagem de "trabalho de formiga", i.e., um tipo de trabalho que requer os esforços coordenados de muitos participantes. ${ }^{87}$ Dez anos após a morte de Iarkhó, seu

задается метрической схемой, которую он ощущает в качестве некоторого ритмико-мелодического рисунка, в пределах которого «укладываются» слова. Воплощаясь в слове, ритмический импульс находит выражение в конкретном ритме отдельных стихов. [...] Слушатель воспринимает ритм в обратном порядке. Сперва ему представляется конкретный ритм стиха. Затем, под впечатлением повтора ритмической линии, в результате восприятия серии стихов, слушатель улавливает ритмический импульс [...] Еще более абстрагируя ритмический строй, он обнаруживает обнажаемую скандовкой метрическую схему." Cf.: JIRMÚNSKI, 1925, p. $67,71$.

84 ČERVENKA, 1984, p.30.

85 Ver: PILSHCHIKOV, 2017a, p.16; PILSHCHIKOV, 2019, p.66-68.

86 FISCHER, AKIMOVA, OREKHOV, 2019.

87 IARKHÓ, 2006, p.554. No original russo: «муравьиная» работа. 
irmão Grigori tentou publicar obras do irmão, tendo se deparado com a seguinte objeção: por que o povo soviético deveria fazer aquela quantidade imensa de cálculos se ainda não se sabia quão úteis eles poderiam ser para a economia do povo? Hoje essas objeções não têm mais razão de ser, isso porque muito deste trabalho pode ser feito por um computador e porque o trabalho demandaria muito menos tempo - atualmente este tipo de operação pode ser feito dezenas, centenas ou até milhares de vezes mais rápido. É justamente neste ponto que o novo formalismo "computacional" de Moretti vem auxiliar o "velho" formalismo literário quantitativo.

As metodologias de Moretti e de Iarkhó são tipologicamente similares em algumas de suas características; sirvam de exemplo os interesses de ambos pelas analogias entre a literatura e a biologia. Entretanto, até bem recentemente, as chamadas "humanidades digitais" ainda não estavam familiarizadas com "os estudos literários exatos" de Iarkhó. Primeiro porque até 2006 sua Metodologia só era conhecida por meio do relato de Mikhail Gasparov em seu artigo pioneiro de $1969,{ }^{88}$ estudo no qual foram incluídos alguns poucos exemplos de cálculos específicos. Também porque as obras de Iarkhó sobre o gênero dramático foram publicadas demasiadamente tarde (19972000). ${ }^{89} \mathrm{Em}$ segundo lugar, isso também se deve à ausência de traduções de Iarkhó para outros idiomas, um número muito reduzido de pesquisadores tinham conhecimento das obras dele até recentemente (rossica non leguntur). Trinta anos se passaram entre a primeira e a segunda tradução de Iarkhó para o inglês, e mesmo em alguns poucos excertos e análises de seus trabalhos que saíram em inglês, o que se prioriza são seus métodos de análise "morfológica" (estrutural), em vez de uma suma de seus métodos quantitativos para estudar literatura. ${ }^{90}$ Somente em 2019, o JLT: Journal of Literary Theory publicou uma tradução do $A$ Distribuição da fala na tragédia

88 Como na nota 51 acima.

89 Como nas notas 53 e 54 acima.

90 Ver: IARKHÓ, 1977; MARGOLIN, 1979; IARKHÓ, 2016. 
de 5 atos (Распределение речи в пятиактной трагедии). ${ }^{91}$ Outro trabalho já mencionado - Comédias e tragédias de Cornelle (Комедии и трагедии Корнеля) que leva o subtítulo de Um estudo sobre a teoria dos gêneros (Этюд по теории жанра), - ainda aguarda seu tradutor. ${ }^{92}$

Na Metodologia, de Iarkhó, os resultados desses estudos são utilizados por meio de alguns poucos exemplos entre centenas de outros. De interesse especial é a seção em que ele demonstra como o estudo da literatura pode se beneficiar das aplicações de métodos estatísticos básicos (construir uma amostra, calcular o intervalo de variação, a média, o modo, a média aritmética, o desvio-padrão, etc.) e como as interpretações significativas desses dados podem ser contribuintesr, i.e., como esses dados explicam as particularidades da estrutura literária ou da evolução literária. ${ }^{93}$ Esta é uma das razões pelas quais a tradução desta obra - ou ao menos de seus fragmentos mais instrutivos - para outras línguas é importante. Iarkhó não considerava sua pesquisa um trabalho concluído, mas apenas o começo de uma tarefa muito mais ampla, o esboço para investigações futuras: "Nós apontamos a técnica, o caminho está liberado para os mais afortunados que nós".94

\section{Referências bibliográficas}

ALLISON, Sarah; HEUSER, Ryan; JOCKERS, Matthew; MORETTI, Franco; WITMORE, Michael. Quantitative Formalism: an Experiment. Stanford Literary Lab. Pamphlet 1, 2011. Disponível em: https://litlab.stanford.edu/LiteraryLabPamphlet1.pdf

91 Ver nota 53.

92 Ver nota 54. Deve ser lembrado aqui que Quantitative Formalism de Jockers, Moretti e seus coautores, é também dedicado ao problema de como fazer distinção entre gêneros se valendo de características quantitativas.

93 IARKHÓ, 2006, p. 117-206.

94 IARKHÓ, 2006, p. 605. No original russo: "Техника работы нами показана, и путь открыт для более счастливых." 
BAILEY, James. "The Russian Linguistic-Statistical Method for Studying Poetic Rhythm: A Review Article." Slavic and East European Journal, 23.2, 1979, p. 251-261.

BIÉLI, Andrei. Simvolizm: Kniga statei. Moscou: Musaget, 1910. BRIK, Óssip. "Ritm i sintaksis" Novyi Lef, № 3: 15-20; № 4: 2329; № 5: 32-37; № 6, 1927, p. 33-39.

CARPI, Guido. "Per una scienza esatta della letteratura: Jarcho e la sua metodologia." Russica Romana, XIV, 2006, p. 145-151.

ČERVENKA, Miroslav. "Ritmítcheskii impuls tchechkogo stikha" In: JAKOBSON, Roman; VAN SCHOONEVELD, C.H.; WORTH, Dean S. (eds.) Slavic Poetics: Essays in honor of Kiril Taranovsky. The Hague, Paris: Mouton, 1973, p.. 79-90.

ČERVENKA, Miroslav. "Der versologische Band von Jakobsons 'Selected Writings' (Bemerkungen eines Bohemisten)". Übersetzt von Christa Hansen-Löve. Wiener Slawistischer Almanach 7, 1981, p. 259-275.

ČERVENKA, Miroslav. "Rhythmical Impulse: Notes and Commentaries." Wiener Slawistischer Almanach 14, 1984, p. 23-53.

CHAPIR, Maksim. "Semantítcheskii oreol metra": termin i poniatie (Istoriko-stikhovedtcheskaia retrospektsiia)". Literatúrnoe obozrenie, 1991, № 12, p. 36-40.

CHAPIR, Maksim. "Moskovskii lingvistitcheskii krujok" In: NIKOLIÚKIN, Aleksandr (ed.). Literatúrnaia entsiklopediia terminov i poniatii. Moscou: Intelvak, 2001, p. 591-594.

CHKLÓVSKI, Víktor. "Izutchenie teôrii poetitcheskogo iazyka" Jizn Iskusstva 273, 1919, p .2.

CHRISTIANSEN, Broder. Philosophie der Kunst. Hanau: Clauss und Feddersen, 1909.

CHRISTIANSEN, Broder. Filosôfiia iskusstva. Trad. por Geórgi Fedótov, ed. por Evgéni Anítchkov. São Petersburgo: Chipóvnik, 1911.

CHÚBIN, Vladimir. Iurii Tynianov: Biobibliografitcheskaia khronika (1894 1943). São Petersburgo: Ársis, 1994.

DAVYDOV, Sergei. "From 'Dominant' to 'Semantic Gesture': A Link between Russian Formalism and Czech Structuralism." 
In: JACKSON, Robert L., RUDY, Stephen(ed.) Russian Formalism: A Retrospective Glance. A Festschrift in Honor of Victor Erlich. (Yale Russian and East European Publications 6). New Haven: Yale Center for International and Area Studies, 1985, p. 96-113.

DEPRETTO, Catherine. "La question du formalisme moscovite." Revue des études slaves 79.1/2, 2008, p. 87-101.

DEPRETTO, Catherine. "Formalisme et poétique. Boris Tomaševskij, le formaliste oublié." Communications 103, 2018, p. 107-118.

DMÍTRIEV, Aleksandr. "Kak sdelana "formalno-flosôfskaia chkola" (ili potchemu ne sostoialsia moskovskii formalzm?) " In: KÓLEROV, Modést A.; PLÓTNIKOV, Nikolai S. (ed.) Issledovaniia po istorii russkoi mysli. Ejegodnik za 20062007 god (8). Moscou: Modést Kólerov, 2009, p. 71-96.

Documentos do CLM - Otdel lingvistítcheskogo istotchnikovedieniia i istorii rússkogo literatúrnogo iazyka Instituta rússkogo iazyka im. V. V. Vinogradova Rossiiskoi akademii nauk, fond 20.

EIKHENBAUM, Boris. Melodika rússkogo liritcheskogo stukha (Sborníki po teôrii poetitcheskogo iazyka s.n). Petersburgo: OPOIAZ, 1922a.

EIKHENBAUM, Boris. Molodôi Tolstói. Petersburgo, Berlim: Izdátel'stvo Z.I. Grjébina, 1922b.

EIKHENBAUM, Boris. "Teôriia 'formalnogo metoda". In: Literatura: Teôriia. Kritika. Polemika. Leningrado: Priboi, 1927 [1925], p. 116-148.

ERLICH, Victor. Russian Formalism: History - Doctrine. The Hague: Mouton, 1955; Segunda edição revisada: 1965.

FISCHER, Frank; AKIMOVA, Marina; OREKHOV, Boris. "Data-Driven Formalism." Journal of Literary Theory 13.1, 2019, p. 1-12.

FLEISHMAN, Lazar'. "Tomachévskii i Moskovskii lingvistitcheskii krujok". Utchionye zapiski Tartuskogo gosudárstvennogo universiteta 422 (Trudy po znakôvym sistemam IX). Tartu: Universidade de Tartu, 1977, p. 113-132. 
GASPAROV, Mikhail. "Rabôty B. I. Iarkho po teôrii literatúry". Utchionye zapiski Tartuskogo gosudárstvennogo universiteta 236 (Trudy po znakôvym sistemam IV). Tartu: Universidade de Tartu, 1969, p. 504-514. [Uma versão revisada em: GASPAROV, Mikhail. Izbrannye trudy. T. 2: O stikhakh.. Moscou: Iazykí rússkoi kul'túry, 1997, p. 468-484.]

GASPAROV, Mikhail. "Kvantitatívnye métody v rússkom stikhovedênii: itogi i perspektivy". In: Sovremennyi rússkii stikh: Métrika i ritmika. Moscou: Nauka, 1974, p. 18-38.

GASPAROV, Mikhail. "Bielyi-stikhoved i Bielyi-stikhotvorets" In: LESNÉVSKI, Stanisláv; MIKHÁILOV, Aleksandr (ed.). Andrei Bielyi: Problemy tvôrtchestva. Moscou: Sovétski pisátel', 1988, pp. 444-460.

GASPAROV, Mikhail. Izbrannye trudy. T. 3: O stikhe. Moscou: Iazikí rússkoi kul'túri, 1997, p. 234-258: "Rússkii gueksametr i inye natsionalnye formy gueksametra ".

HANSEN-LÖVE, Aage A. Der russische Formalismus: Methodologische Rekonstruktion seiner Entwicklung aus dem Prinzip der Verfremdung. Wien: Verlag der Österreichischen Akademie der Wissenschaften, 1978.

HANSEN-LÖVE, Aage A. "Dominanta" Russian Literature 19.1 (1986), p. 15-25.

IARKHÓ, Boris. "Proteichie osnovániia formalnogo analiza" In: Ars poetica I. Moscou: Izdánie GAKhN, 1927, p. 7-28.

IARKHÓ, Boris. "Methodology for a Precise Science of Literature: (Outline)." Trans. by L.M. O'Toole. In: Russian Poetics in Translation. Vol. 4: Formalist Theory. Colchester, Oxford: Holdan, 1977, p. 52-70.

IARKHÓ, Boris. "Raspredelenie retchi v piatiaktnoi traguédii (K voprôsu o klassitsizme i romantizme)" Ed. por Marina Akimova. Prefácio de Maksim Shapir. Philologica 4, 1997, p. 201-287.

IARKHÓ, Boris. "Komédii i traguédii Kornelia (Etiud po teôrii janra)." Ed. por Marina Akimova. Philologica 6, 1999/2000, p. 143-319.

IARKHÓ, Boris. Metodolôguia tôtchnogo literaturovedêniia: Izbrannyie trudy po teôrii literatúry. Ed. por Marina Akimova, 
Igor Pilshchikov, e Maksim Chapir (editor geral). Moscou: Iazykí slaviánskikh kul'túr, 2006.

IARKHÓ, Boris. "The Elementary Foundations of Formal Analysis." Trans. by Michael Lavery and Igor Pilshchikov. Studia Metrica et Poetica 3.2, 2016, p. 151-174.

IARKHÓ, Boris. "Speech Distribution in Five-Act Tragedies (A Question of Classicism and Romanticism)." Trans. by Craig Saunders. Journal of Literary Theory 13.1, 2019, p. 13-76.

JAKOBSON, Roman. Noveichaia rússkaia poeziia. Nabrôsok pérvyi. Praga: Politika, 1921.

JAKOBSON, Roman. O tchechskom stikhe: preimuschestvenno $v$ sopostavlenii s rússkim (Sborníki po teôrii poetitcheskogo iazyka 5. Moscou, Berlim: OPOIAZ - MLK, 1923.

JAKOBSON, Roman "Poznámky k dílu Erbenovu: II. O verši." Slovo a slovesnost 1.4, 1935, p. 218-229.

JAKOBSON, Roman. "K popisu Máchova verše." In: Jan Mukařovský (ed.) Torso a tajemství Máchova díla: Sborník pojednání Pražského linguistického kroužku. Praha: Fr. Borový, 1938, p. 207-278.

JAKOBSON, Roman. "Postscript." In: BRIK, Osip. Two Essays on Poetic Language (Michigan Slavic Materials 5). Ann Arbor, 1964, p. 77-81. [Republicado sob o título "Osip Maksimovič Brik". In: JAKOBSON, Roman. Selected Writings. Vol. V: On Verse, Its Masters and Explorers. The Hague, Paris, New York: Mouton, 1979, p. 557-559.]

JAKOBSON, Roman. "Linguistics and Communication Theory". In: Selected Writings. Vol. II: Word and Language. The Hague: Mouton, 1971 [1960], p. 570-579 [1960].

JAKOBSON, Roman. "An Example of Migratory Terms and Institutional Models (On the Fiftieth Anniversary of the Moscow Linguistic Circle)" In: Selected Writings. Vol. II: Word and Language. The Hague: Mouton, 1971 [1965], p. 527-538: .

JAKOBSON, Roman. "Toward a Description of Mácha's Verse". In: Selected Writings. Vol. V: On Verse, Its Masters and Explorers. The Hague, Paris, New York: Mouton, 1979 [1938], p. 433485. Trans. by Peter and Wendy Steiner. 
JAKOBSON, Roman. "Moskôvskii lingvistitcheskii krujok" Ed. com introdução e notas por Maksim Chapir. Philologica 3, 1996, p. 361-380.

JAKOBSON, Roman. Formalistická škola a dnešní literární věda ruská. Brno 1935. Ed. Tomáš Glanc. Praha: Academia, 2005.

JIRMÚNSKI, Víktor. Rifma, eio istôria i teôria (Voprôsy poetiki III). Petersburgo: Academia, 1923.

JIRMÚNSKI, Víktor. Vvedenie $\mathrm{v}$ metriku : Teôria stikha (Voprôsy poetiki VI). Leningrado: Academia, 1925.

KLIGER, Ilya; MASLOV, Boris. "Introducing Historical Poetics: History, Experience, Form." In: KLIGER, Ilya; MASLOV, Boris (ed.) Persistent Forms: Explorations in Historical Poetics. Bronx, N.Y.: Fordham University Press, 2016, p. 1-36.

KRUSÁNOV, Andrei. Rússkii avangard: 19071932 (Istorítcheskii obzor). T. 2: Futuristitcheskaia revoliutsiia (1917 1921). Kn. 1. Moscou: Nóvoe literatúrnoe obozrénie, 2003.

LEVCHENKO, Jan; PILSHCHIKOV, Igor. "Vmêsto predislôvia" In: LEVCHENKO, Jan; PILSHCHIKOV, Igor (ed.). Epôkha "ostranêniia": Rússkii formalizm i sovremennoe gumanitarnoe znanie. Moscou: Nóvoe literatúrnoe obozrénie, 2017, p. 5-10.

MARGOLIN, Uri. "B.I. Yarkho's Programme for a Scientifically Valid Study of Literature." Essays in Poetics 4.2, 1979, p. 1-36.

MATĚJKA, Ladislav; POMORSKA, Krystyna (eds.). Readings in Russian Poetics: Formalist and Structuralist Views. Cambridge, Mass.: The MIT Press, 1971.

PILSHCHIKOV, Igor [PIL'ŠČIKOV, Igor']. "Il retaggio scientifico del formalismo russo e le scienze umane moderne." Trad. e introduzione di Cinzia Cadamagnani. Enthymema V, 2011, p. 70-102. Disponível em: https://riviste.unimi.it/index.php/enthymema/article/view/1751

PILSHCHIKOV, Igor [PIL'ŠČIKOV, Igor'. "Nasledie russkoi formalnoi chkoly i sovremennaia filolôgiia". Antropolôguia kultury 5, 2015, p. 319-350.

PILSHCHIKOV, Igor [PIL'ŠČIKOV, Igor'. "The Inner Form of the Word' in Russian Formalist Theory." In: Michał Mrugalski, 
Schamma Schahadat (eds.) Theory of Literature as a Theory of the Arts and the Humanities (Wiener Slawistischer Almanach, Sonderband 92). Leipzig, Wien: Biblion Media, 2017a, p. 37-64.

PILSHCHIKOV, Igor [PIL'ŠČIKOV, Igor'. “Заседание Московского лингвистического кружка 1 июня 1919 г. и зарождение стиховедческих концепций О. Брика, Б. Томашевского и Р. Якобсона." Revue des études slaves 88.1/2 (2017b): 151-175.

PILSHCHIKOV, Igor [PIL'ŠČIKOV, Igor'. "Franko Moretti i nôvyi kvantitativnyi formalizm". Nôvoe literatúrnoe obozrenie 150, 2018, p. 39-45.

PILSHCHIKOV, Igor [PIL'ŠČIKOV, Igor'. "Rhythmical Ambiguity: Verbal Forms and Verse Forms," Studia Metrica et Poetica 6.2 (2019): 53-73.

PILSHCHIKOV, Igor [PIL'ŠČIKOV, Igor'; USTINOV, Andrei. "Debiut Víktora Chklovskogo v Moskôvskom Lingvistítcheskom Krujke: Ot "istorii romána" k "razvertyvániiu siujeta". Literatúrnyi fakt 9, 2018a, p. 314-334.

PILSHCHIKOV, Igor [PIL'ŠČIKOV, Igor'; USTINOV, Andrei "Víktor Chklovskii v OPOIAZe i Mosôvskom Lingvistitchêskom Krujke (1919-1921 gg.)" Wiener Slavistisches Jahrbuch. Neue Folge 6, 2018b, p. 176-206.

PILSHCHIKOV, Igor [PIL'ŠČIKOV, Igor'; USTINOV, Andrei. "Moskôvskii Lingvistitcheskii Krujok i stanovlênie rússkogo stikhovedênia (1919 1920)." Stanford Slavic Studies, vol. 50, 2020, no prelo.

POLILOVA, Vera. "Polémika vokrug sbornikov "khudôjestvennaia fôrma" i "Ars poetica": B. I. Iarkho i Opoiaz" Studia slavica: Sbornik nautchnykh trúdov molodykh filôlogov X. Tallinn: Instituto de Línguas e Culturas Eslavas da Universidade de Tallinn, 2011, p. 153-170.

SANMARTÍN ORTÍ, Pau. Otra historia del formalismo ruso. Madrid: Lengua de Trapo, 2008.

SEEMANN, Klaus Dieter. "Boris Tomaševskij's Theory of Literature." Russian Literature 20.2, 1986, p. 143-158. 
STEINER, Peter. Russian Formalism: A Metapoetics. Ithaca, N.Y., and London: Cornell University Press, 1984.

TIHANOV, Galin. "Russian Formalism." In: The Princeton Encyclopedia of Poetry and Poetics. 4th ed. Princeton: Princeton University Press, 2012, p. 1239-1242.

TIHANOV, Galin. The Birth and Death of Literary Theory: Regimes of Relevance in Russia and Beyond. Stanford: Stanford University Press, 2019.

TÓDDES, Evgéni; TCHUDAKÓV, Aleksandr; TCHUDAKÓVA, Mariétta. "Kommentárii" In: TYNIÁNOV, Iúri. Poétika. Istóriia literatúry. Kino. Moscou: Naúka, 1977, p. 397-572.

TODOROV, Tzvetan. Théorie de la littérature. Textes des Formalistes russes réunis, présentés et traduits par Tzvetan Todorov. Préface de Roman Jakobson. Paris: Seuil, 1965.

TOMACHÉVSKI, Boris. "Piatistópnyi iamb Púchkina" In: Víktor Chklóvski (ed.) Otcherki po poétike Púchkina. Berlim: Epókha, 1923a, p. 7-143.

TOMACHÉVSKI, Boris. Rússkoe stikhoslojénie: Métrika (Voprósy poétiki II). Petrogrado/Petersburgo: Academia, 1923b. TOMACHÉVSKI, Boris. Teóriia literatúry (Poétika). Moscou, Leningrado: Gosudárstvennoe izdátelstvo, 1925. [Segunda edição revisada, 1927. Quinta edição revisada, 1930; Sexta edição, 1931.]

TOMACHÉVSKI, Boris. O stikhe. Leningrado: Priboi, 1929.

TROTSKI, Lev. "Formalnaia chkola poezii i markzism". In: Literatura i revoliutsiia. Moscou: Krásnaia nov', p. 119-135.

TYNIÁNOV, Iúri. Probliema stikhotvornogo iazyka (Voprosy poetiki V). Leningrado: Academia, 1924.

VESSELÓVSKI, Aleksandr. "Iz vvedeniia v istoritcheskuiu poetiku (Voprosy i otviety)" Jurnal Ministerstva narodnogo prosvescheniia 293.5 (1894): Otdél nauk, 21-42.

WELLEK, René, WARREN, Austin. Theory of Literature. Harmondsworth: Peregrine Books, 1949. [Segunda edição revisada New York: Harcourt, Brace and World, 1956; Third edition, 1963.] 
WELLEK, René, WARREN, Austin . "The Main Trends of Twentieth-Century Criticism." The Yale Review 51.1 (1961): 102-118.

Tradução de Valteir Vaz

Recebido em: 27/07/2020

Aceito em: 25/08/2020

Publicado em setembro de 2020 